Article

\title{
Bioactive Compounds from Norway Spruce Bark: Comparison Among Sustainable Extraction Techniques for Potential Food Applications
}

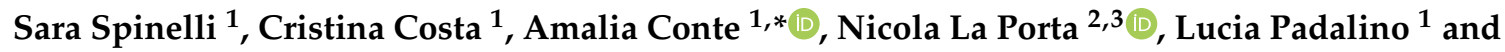 \\ Matteo Alessandro Del Nobile ${ }^{1}$ \\ 1 Department of Agricultural Sciences, Food and Environment, University of Foggia, Via Napoli, \\ 25-71121 Foggia, Italy; sara.spinelli@unifg.it (S.S.); cristina.costa@unifg.it (C.C.); \\ lucia.padalino@unifg.it (L.P.); matteo.delnobile@unifg.it (M.A.D.N.) \\ 2 Department of Sustainable Agro-ecosystems and Bioresources, Research and Innovation Centre, Fondazione \\ Edmund Mach, Via E. Mach 1, 38010 San Michele all'Adige, Italy; nicola.laporta@fmach.it \\ 3 The EFI Project Centre on Mountain Forests (MOUNTFOR), Via E. Mach 1, 38010 San Michele all'Adige, Italy \\ * Correspondence: amalia.conte@unifg.it; Tel.: +39-088-158-9240
}

Received: 25 September 2019; Accepted: 21 October 2019; Published: 23 October 2019

check for updates

\begin{abstract}
Picea abies (L.) Karst, (Norway spruce) bark, generally considered as wood industry waste, could potentially be used as a valuable source of antioxidants for food applications. In this study, supercritical fluid extraction (SFE), pressurized liquid extraction (PLE), and ultrasound-assisted extraction (UAE) were carried out in order to recover bioactive compounds from bark of Norway spruce. Obtained results show that PLE with ethanol as solvent was the most effective method for extracting total flavonoid compounds (21.14 $\pm 1.42 \mathrm{mg}$ quercetin $\mathrm{g}^{-1}$ sample) and consequently exerted the highest antioxidant activity measured by 2,2'-azino-bis (3-ethylbenzothiazoline-6-sulfonic

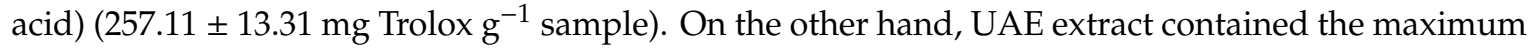

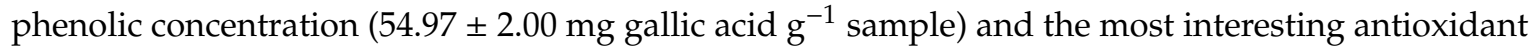
activity measured by the ferric-reducing antioxidant power $\left(580.25 \pm 25.18 \mu \mathrm{mol} \mathrm{FeSO}_{4} \mathrm{~g}^{-1}\right.$ sample). Additionally, PLE and UAE have demonstrated great efficiency in the extraction of trans-resveratrol,

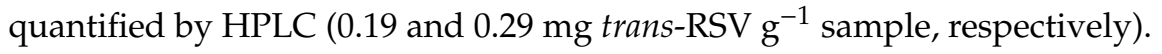

Keywords: supercritical fluid extraction; pressurized liquid extraction; ultrasound-assisted extraction; trans-resveratrol; Norway spruce bark

\section{Introduction}

Annually, a considerable amount of bark waste is generated as by-product from the industrial wood transformation. This waste is usually discarded or used for energy, biogas production, or animal feed [1]. Nevertheless, it is known that tree barks contain a wide variety of bioactive compounds [2]. In particular, several authors have found a large amount of phenolic antioxidants in bark of Picea abies (Norway spruce), one of the most distributed conifer species in Eurasian forests [3-5]. Spruce bark is especially rich in glycosylated monomeric stilbenes (astringin, piceid, and isorhapontin) and their corresponding aglycone forms (piceatannol, resveratrol, and isorhapontigenin) [6]. Among these different kinds of stilbenes, trans-resveratrol (trans-3, 5, 4' -trihydroxystilbene; trans-RSV) has attracted great attention. It is a natural polyphenolic compound found in a variety of food and also in bark tree [7]. Actually, it is considered a powerful compound capable to improve health and prevent chronic disease in human [8,9]. Recently published studies have shown that resveratrol can also protect against some neurodegenerative diseases, obesity and diabetes [10], high blood pressure [11], as well as cancer [12] and osteoporosis [9]. In addition, it is widely used in cosmetics and dermatology [13]. 
Even though basic extractions from spruce bark do not represent a novelty in the literature $[1,3,14,15]$, specific comparisons among available techniques are still very few.

Nowadays, there is a great attention to green extraction technologies able to reduce or eliminate the use of hazardous substances and limit the cost of solvent waste disposal [16]. Among them, a prominent position can be occupied by supercritical fluid extraction (SFE), pressurized liquid extraction (PLE), and ultrasound-assisted extraction (UAE), all considered sustainable techniques [17-19]. SFE is considered a fast, efficient, and clean method [20]. Carbon dioxide is the most common gas used as supercritical fluid due to its moderate critical temperature and pressure $\left(31.3{ }^{\circ} \mathrm{C}\right.$ and $72.9 \mathrm{~atm}$, respectively) [17]. Applications for the extraction of essential oils, tocotrienols, alkaloids, phenolic compounds, carotenoids, and tocopherols from different food matrices were carried out [17,21,22]. PLE is a technique that uses liquid solvents at elevated pressure and temperature to enhance the extraction performance [19]. The PLE system provides protection to oxygen- and light-sensitive compounds and improves the extraction yield, thus also decreasing time and solvent consumption $[19,23,24]$. UAE is another efficient extraction method, with high reproducibility, which requires low energy and minimum consumption of solvent. Aromas, phenols, antioxidant pigments, and low-molecular-weight compounds have been extracted by this technique [18]. The extraction of antioxidant compounds and in particular of resveratrol from spruce bark could be an efficient way to reuse and enhance this voluminous biomass waste.

The aim of this work was to compare the extracts of Norway spruce bark obtained by SFE, PLE, and UAE. In particular, total extract yield (TEY), total phenolic content (TPC), total flavonoid content (TFC), and antioxidant capacity were measured to compare the efficacy of each technique. Chromatographic identification of trans-RSV was also performed for the extracts with the highest polyphenols content.

\section{Materials and Methods}

\subsection{Wood Materials and Chemicals}

Norway spruce bark was supplied by the timber sawmill company Vender Legnami s.r.l. (Trento, Italy) and dried at room temperature for two weeks. The bark was collected in July 2018, obtained by a stock of timber logs processed and debarked by the company. The spruce logs were coming from Trentino forests (Italy) at their final cutting phase. The trees were growing at an elevation ranging from 1000 to $1600 \mathrm{~m}$ a.s.l. The tree age was ranging from 90 to 110 years old. The bark thickness was ranging from 4 to $10 \mathrm{~mm}$. The barks were ground in a knife mill at room temperature, and the powdered bark was sieved to select particles smaller than $1 \mathrm{~mm}$.

Standard trans-resveratrol (3,5,4'-trihydroxystilbene) and all analytical grade reagents were purchased from Sigma-Aldrich (Milano, Italy). $\mathrm{CO}_{2}$ with purity degree of 4.5 was supplied by Sapio (Monza, Italy), while $\mathrm{N}_{2}$ with purity degree of $99.9 \%$ was provided by Air Liquide (Milan, Italy).

\subsection{Supercritical Fluid Extraction}

Supercritical fluid extractions from bark were carried out in triplicate with a Speed SFE-2 extractor (Applied Separation, Allentown, PA, USA). In particular, different concentrations of ethanol (10, 20, 40, and $70 \% ; v / v$ ) were tested (SFE_10, SFE_20, SFE_40, and SFE_70, respectively). According to Talmaciu et al. [14], for aqueous ethanol as co-solvent, a pressure of 100 bar and a temperature of $40{ }^{\circ} \mathrm{C}$ for a static time of $150 \mathrm{~min}$ and a dynamic time of $105 \mathrm{~min}$ were used. An amount of $2 \mathrm{~g}$ of spruce bark was used for all the experiments. Extractions were performed with $6 \mathrm{~mL} / \mathrm{min}$ flow rate in the static phase and with $\mathrm{CO}_{2}$ and ethanol as co-solvent, with $10: 1 \mathrm{~mL} / \mathrm{min}$ flow rate ratio for the dynamic phase.

\subsection{Pressurized Liquid Extraction}

Pressurized liquid extractions were performed in triplicate on a PLE-1 system (LabService Analytica srl, Anzola Emilia, Italy) using distillate water at $160{ }^{\circ} \mathrm{C}\left(\mathrm{PLE}_{-} \mathrm{H}_{2} \mathrm{O}\right)$ and absolute ethanol at 
$180^{\circ} \mathrm{C}$ (PLE_EtOH) as solvent, according to Co et al. [3]. In particular, the extraction method included different steps: sample load into cell ( $30 \mathrm{~g})$; cell preparation ( $3 \mathrm{~min})$; pressurization and heating ( $5 \mathrm{~min}$, 50 bar, and $160{ }^{\circ} \mathrm{C}$ or $180^{\circ} \mathrm{C}$ for ethanol and water, respectively); depressurization ( $\left.0.1 \mathrm{~min}\right)$; flush volume $(60 \%)$, and finally, $\mathrm{N}_{2}$ purge $(2 \mathrm{~min})$. To remove any process carryover, a washing cycle was made among the extractions.

\subsection{Ultrasound-Assisted Extraction}

Ultrasound-assisted extractions were performed in triplicate using an ultrasonic bath CP104 (C.E.I.A., Viciomaggio, Arezzo, Italy; bath frequency $39 \mathrm{kHz}$, power $200 \mathrm{~W}$ ). The extraction conditions have been set according to the results obtained from Ghitescu et al. [15] for polyphenol recovery in spruce wood bark. In particular, a process time of $60 \mathrm{~min}$, an extraction temperature of $54{ }^{\circ} \mathrm{C}$, a concentration of ethanol of $70 \%(v / v)$, and a material/solvent ratio of 1:10 were taken into account.

\subsection{Chemical Characterization}

\subsubsection{Total Extraction Yield (TEY)}

The extracts were evaporated overnight in a vacuum oven (OPTO-LAB, Concordia, Modena, Italy) at $30^{\circ} \mathrm{C}$, and the obtained final mass was weighted to calculate the TEY. Prior to analysis, each extract recovered with ethanol $(20 \mathrm{~mL})$ was stored in the dark at $4{ }^{\circ} \mathrm{C}$. Results were expressed as $\mathrm{mg}$ of dry extract per gram of samples.

\subsubsection{Total Phenolic Content (TPC)}

TPC was spectrophotometrically measured using Folin-Ciocalteu reagent, according to conditions previously described by Spinelli et al. [22]. The total phenol contents were evaluated using a standard curve with different gallic acid concentrations $\left(3.125-100 \mathrm{mg} \mathrm{L}^{-1} ; R^{2}=0.99\right)$. Results were expressed as $\mathrm{mg}$ gallic acid equivalents per gram of dry weight $(\mathrm{dw})$.

\subsubsection{Total Flavonoid Content (TFC)}

The aluminum trichloride method was carried out to determine TFC, as described by Spinelli et al. [22]. The calibration curve was made with standard solutions of quercetin $(6.25-400 \mathrm{mg}$ $\mathrm{L}^{-1} ; R^{2}=0.99$ ) in order to express the total flavonoid content as mg quercetin equivalent per gram of dry weight $(\mathrm{dw})$.

\subsubsection{Antioxidant Activity}

The ABTS [2,2' -azino-bis(3-ethylbenzothiazoline-6-sulfonic acid)] assay was measured as described by Marinelli et al. [25]. The ABTS values were calculated from a standard curve of different concentrations of Trolox $\left(3.125-600 \mathrm{mg} \mathrm{L}^{-1} ; R^{2}=0.99\right)$. The radical scavenging capacity of extracts was quantified as $\mathrm{mg}$ Trolox equivalent per gram of dry weight $(\mathrm{dw})$.

The antioxidant capacity of extracts was also estimated in another assay, according to the FRAP (ferric reducing antioxidant power) procedure described by Lucera et al. [26]. For determination, a calibration curve of ferrous sulfate heptahydrate $\left(\mathrm{FeSO}_{4} \cdot 7 \mathrm{H}_{2} \mathrm{O}\right)$ was prepared, with dilutions from $600 \mu \mathrm{mol}$ to $12.5 \mu \mathrm{mol}\left(R^{2}=0.99\right)$.

\subsection{HPLC Analysis of Trans-Resveratrol}

Chromatographic identification of trans-RSV was performed using an Agilent 1100-Series HPLC system (Agilent Technologies Inc, Santa Clara, CA, USA), equipped with a degasser, binary pump solvent delivery, auto sampler, column oven, and DAD detector. An Agilent Zorbax Eclipse C18 $(4.6 \times 150 \mathrm{~mm} ; 5 \mu \mathrm{m}$ particles $)$ and a guard column of the same stationary phase were used for trans-RSV separation. HPLC analysis was performed using the conditions described by Sun et al. [27] with slight modification, consisting of an isocratic elution by methanol-water (40:60 by volume). The 
flow rate was $1 \mathrm{~mL} \mathrm{~min}^{-1}$, UV detection wavelength $300 \mathrm{~nm}$, injection volume $10 \mu \mathrm{L}$, and column temperature $25^{\circ} \mathrm{C}$. The working standard solutions of trans-RSV $\left(0.01-100 \mathrm{mg} \mathrm{L}^{-1}\right)$ were prepared by diluting the stock solution $\left(250 \mathrm{mg} \mathrm{L}^{-1}\right)$ in mobile phase and stored at $4{ }^{\circ} \mathrm{C}$ in darkness to avoid oxidative degradation and isomerization of trans-RSV to cis-form. The method linearity was up to $100 \mathrm{mg} \mathrm{L}^{-1}$. The identification of trans-RSV in the extracts was performed by comparison of the retention time ( $7.5 \mathrm{~min})$ and UV spectra with trans-RSV standard.

\subsection{Statistical Analysis}

A one-way ANOVA and a post-hoc Fisher's test were used to evaluate statistically significant differences among samples. The software was Statistica 7.1 for Windows (StatSoft Inc., Tulsa, OK, USA). All tests were carried out in triplicate.

\section{Results and Discussion}

In this study, three different extraction techniques, that is, supercritical fluid extraction, pressurized liquid extraction, and ultrasound-assisted extraction, were compared in order to obtain a valuable spruce bark extract rich in bioactive compounds with high antioxidant activity.

\subsection{Supercritical Fluid Extraction}

Table 1 summarizes the experimental results of the SFE, in terms of total extraction yield (TEY), total phenolic content (TFC), total flavonoid content (TFC), and antioxidant activity.

Table 1. Total extraction yield (TEY), total phenolic content (TPC), total flavonoid content (TFC), and antioxidant activity (ABTS and FRAP) of SFE spruce extracts with different ethanol concentrations: SFE_10 $(10 \% ; v / v) ;$ SFE_20 $(20 \% ; v / v)$; SFE_40 $(40 \% ; v / v)$.

\begin{tabular}{|c|c|c|c|c|c|}
\hline & TEY & TPC & TFC & ABTS & FRAP \\
\hline & $\mathrm{mg} / \mathrm{g} \mathrm{dw}$ & mg GAEs/g dw & mg QEs/g dw & $\mathrm{mg}$ TEs/g dw & $\mu \mathrm{mol} \mathrm{FeSO}{ }_{4} \cdot 7 \mathrm{H}_{2} \mathrm{O} / \mathrm{g} \mathrm{dw}$ \\
\hline SFE_10 & $28.6 \pm 0.36^{\mathrm{a}}$ & $0.77 \pm 0.02^{\mathrm{a}}$ & $0.47 \pm 0.02^{\mathrm{a}}$ & $2.48 \pm 0.13^{a}$ & $8.31 \pm 0.24^{\mathrm{a}}$ \\
\hline SFE_20 & $30.7 \pm 0.96^{\mathrm{a}}$ & $1.24 \pm 0.07^{b}$ & $1.05 \pm 0.15^{b}$ & $3.08 \pm 0.16^{b}$ & $10.01 \pm 0.81^{b}$ \\
\hline SFE_40 & $31.2 \pm 0.21^{\mathrm{a}}$ & $2.50 \pm 0.03^{c}$ & $1.75 \pm 0.10^{c}$ & $5.29 \pm 0.04^{c}$ & $25.49 \pm 0.66^{c}$ \\
\hline
\end{tabular}

Values are means of three replications \pm standard deviation. Values in the same column followed by different superscript letters differ significantly $(p<0.05)$. SFE: supercritical fluid extraction. GAEs: gallic acid equivalents; QEs: quercetin equivalent; TEs: Trolox equivalent; $\mathrm{FeSO}_{4} \cdot 7 \mathrm{H}_{2} \mathrm{O}$ : ferrous sulfate heptahydrate; $\mathrm{ABTS}$ : 2,2'-azinobis (3-ethylbenzothiazoline-6-sulfonic acid). FRAP: ferric reducing antioxidant power.

Concerning the TEY, the amount of ethanol did not influence the extraction yield. Comparable results were recorded, even though some differences in the chemical composition of the extract were found. As can be seen in the Table 1, the gradual increase of ethanol in the SFE statistically improves the extraction capacity of phenolic compounds, flavonoids, and antioxidant activity of spruce extracts [28]. In particular, TPC steadily increased as the ethanol concentration increased (from $0.77 \pm 0.02$ to $2.50 \pm 0.03 \mathrm{mg}$ GAEs/g dw), and a similar behavior was also observed for TFC, with the highest value $1.75 \pm 0.10 \mathrm{mg}$ QEs/g dw in the assay SFE_40. Similarly, SFE_40 shows the radical scavenging ABTS and FRAP capacity respectively 2 and 3 times higher than that obtained with SFE_10. It is well known that ethanol promotes the recovery of polar compounds from the samples due to changes in the extractive properties (diffusivity, density, and viscosity); in fact, the purpose of ethanol is to swell plant cells, thus allowing both solvent penetration and diffusion of the solute in the solid matrix. In this way, both the increase in polarity of supercritical $\mathrm{CO}_{2}$ and the rapid formation of interactions with the analyte of interest are promoted [29]. A similar behavior was also reported in several previous studies that demonstrated how ethanol enhanced the extraction of bioactive compounds and consequently improved the antioxidant activity. Conde et al. [30] used supercritical $\mathrm{CO}_{2}$ to extract phenolic compounds from Pinus pinaster wood and noted that the extraction yield and 
the phenolic concentration increased when ethanol was used as co-solvent. Fabrowska et al. [31] also developed a supercritical fluid extraction process in order to revalorize different freshwater green macro-algae species, demonstrating that the increase in the concentration of ethanol from $0 \%$ to $15 \%$ resulted in an increase in the extraction yield and in bioactive compound concentrations. Our assay with $70 \%$ of ethanol solution allowed recording extract statistically poorer in phenol and flavonoid content compared with the assay with lower ethanol concentrations (data not shown). As also reported in the literature, the use of high concentration of co-solvent can sometimes provoke reduction of target bioactive compounds, due to interactions between $\mathrm{CO}_{2}$ and co-solvent [32].

\subsection{Pressurized Liquid and Ultrasound-Assisted Extraction}

In Table 2 are reported the TEY, TPC, TFC, and the antioxidant activity for Norway spruce bark extracts obtained by PLE and UAE techniques.

Table 2. Total extraction yield (TEY), total phenolic content (TPC), total flavonoid content (TFC), and antioxidant activity (ABTS and FRAP) of PLE and UAE spruce extracts with water (PLE_H $\left.\mathrm{H}_{2} \mathrm{O}\right)$ and absolute ethanol (PLE_EtOH and UAE_EtOH).

\begin{tabular}{|c|c|c|c|c|c|}
\hline & TEY & TPC & TFC & ABTS & FRAP \\
\hline & $\mathrm{mg} / \mathrm{g} \mathrm{dw}$ & mg GAEs/g dw & mg QEs/g dw & mg TEs/g dw & $\mu \mathrm{mol} \mathrm{FeSO}{ }_{4} \cdot 7 \mathrm{H}_{2} \mathrm{O} / \mathrm{g} \mathrm{dw}$ \\
\hline PLE_H $\mathrm{H}_{2} \mathrm{O}$ & $130.7 \pm 8.62^{\mathrm{a}}$ & $33.45 \pm 1.44^{\mathrm{a}}$ & $19.03 \pm 0.98^{\mathrm{a}}$ & $69.87 \pm 1.46^{c}$ & $389.10 \pm 16.87^{b}$ \\
\hline PLE_EtOH & $127.9 \pm 2.52^{a}$ & $46.32 \pm 2.17^{b}$ & $21.14 \pm 1.42^{\mathrm{a}}$ & $257.11 \pm 13.31^{\mathrm{a}}$ & $506.10 \pm 31.37^{a}$ \\
\hline UAE_EtOH & $123.3 \pm 5.77^{a}$ & $54.97 \pm 2.00^{c}$ & $14.44 \pm 1.31^{b}$ & $128.47 \pm 8.61^{b}$ & $580.25 \pm 25.18^{a}$ \\
\hline
\end{tabular}

As regards PLE extract, from a general point of view, the technique is more efficient than SFE, because the working conditions of PLE generally allow protecting of bioactive compounds [33]. In particular, Rostagno et al. [34] described how isoflavones can be extracted by PLE from soybeans without degradation. As can be observed in Table 2, the two different tested solvents did not influence significantly the yield. On the contrary, higher content in TPC, TFC, and radical scavenging ABTS and FRAP were obtained for PLE extraction with absolute ethanol compared with water. Howard and Pandjaitan [35] reported that the flavonoids extracted from spinach by PLE with ethanol were more effective when compared with the same compounds extracted by different conditions. The significant increase in terms of antioxidant capacity, measured by ABTS or FRAP is also in accordance with literature data. Zhao et al. [36] also reported high DPPH (2,2-diphenyl-1-picryl-hydrazyl-hydrate) radical scavenging capacity and total phenolic content in barley extract with ethanol, compared with water extract. In the PLE technique, the application of high temperature during the extraction significantly decreases the dielectric constant of water and cuts down the surface tension, thus promoting the extraction of bioactive compounds, but PLE water extraction can damage some thermolabile compounds, such as polyphenols and flavonoids, thus justifying the preference for ethanol as co-solvent [23].

Results obtained from UAE extraction highlighted that UAE yield was higher than SFE_40 yield and comparable to that of the PLE_EtOH extract. As can be seen in the Table 2, UAE extract exerted the maximum phenolic concentration among the various green techniques adopted $(54.97 \pm 2.00 \mathrm{mg}$ GAEs/g dw). The literature also confirms that UAE applied to various natural matrices significantly increases the phenolic compounds extracted, compared with alternative extraction methods $[19,23]$. As a fact, the production of cavitation bubbles promotes better extraction yield and increases the antioxidant activity of these extracts [37]. A similar trend was also observed when the comparison was made in terms of FRAP-antioxidant activity. 
In order to highlight some possible relationships among the values reported in Table 2, a remarkable correlation between TPC and FRAP assay can be found with both the extraction methods adopted [22]. Thaipong et al. [38], studying the comparison among ABTS, DPPH, FRAP, and ORAC assays for estimating the antioxidant activity of guava fruit extracts, also demonstrated that FRAP test showed high correlation with total phenolic content. Youn et al. [39] also investigated the relationship between antioxidant activity and polyphenol or flavonoid contents in leaf extracts obtained from Dendropanax morbifera LEV. and showed that FRAP value was strongly correlated with polyphenols. A similar correlation can be also observed between total flavonoid compounds and ABTS. Similar trends were also found in other literature data carried out on various medicinal plants $[40,41]$.

The different mechanism of action between FRAP and ABTS assay justifies the different values recorded between them. As a fact, the FRAP assay is based on the singlet electron transfer, while ABTS is based on the mixed mode with singlet electron transfer and hydrogen atom transfer [42].

\subsection{Chromatographic Identification of Trans-RSV}

The spruce bark extracts obtained by the two best extraction techniques in terms of total phenol content (PLE_EtOH and UAE) were also analyzed by chromatographic identification in order to achieve a quantitative and complete characterization of trans-RSV. In Figure 1 is reported the trans-RSV content in PLE_EtOH and UAE extracts. As can be observed, higher levels of trans-RSV were found in UAE extract $(0.29 \mathrm{mg} / \mathrm{g} \mathrm{dw})$. Extraction conditions and isomerization to cis isomer can be the explanation to justify the low content of trans-RSV in PLE extract [43]. Zupancic et al. [44] also highlight that pH, temperature, and different extraction methods influenced trans-RSV stability. Garcìa-Pèrez et al. [45] found resveratrol as the only stilbenes in Picea marina bark extract with ethyl acetate. Differently, Co et al. [3] identified resveratrol in spruce extract with PLE by nuclear magnetic resonance and mass spectrometry detection.

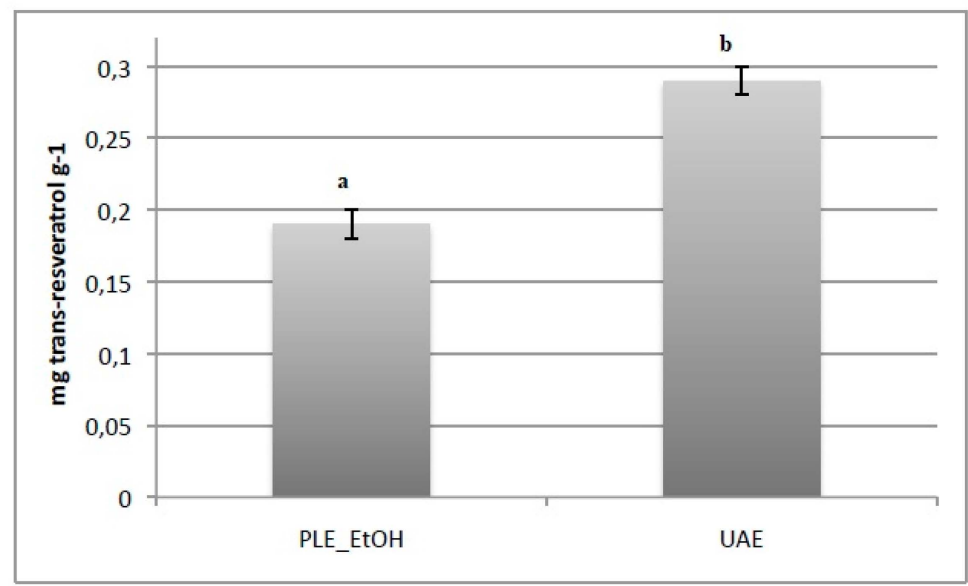

Figure 1. Trans-resveratrol content in PLE and UAE extracts. Samples with different superscript letters differ significantly $(p<0.05)$.

\section{Conclusions}

The results presented in this research show valid means to obtain antioxidant compounds, with a better focus on resveratrol, from Norway spruce bark using different environmental-friendly extraction techniques. In particular, the best results in terms of total phenolic compounds and antioxidant capacity measured by FRAP assays were obtained for UAE extract. PLE extract obtained with absolute ethanol shows the highest total flavonoid content and the best antioxidant capacity measured by ABTS assays. The highest trans-RSV content identified by chromatography was recorded for the UAE extract $(0.29 \mathrm{mg} / \mathrm{g} \mathrm{dw})$, thus suggesting the potential of ultrasound-assisted extraction with ethanol $(70 \%$ 
$v / v$ ) for the valorization of waste, to record antioxidant compounds that can be applied to food and pharmaceutical sectors.

Author Contributions: S.S., C.C., and L.P. carried out experimental data. A.C. and M.A.D.N. elaborated data and contributed to the manuscript writing. N.L.P. contributed to the to the study proposal, to the results evaluation and to the manuscript writing.

Funding: This research was partially co-financed by the Grant P1611034I provided by the Fondazione Edmund Mach.

Conflicts of Interest: The authors declare no conflict of interest.

\section{References}

1. Jablonsky, M.M.; Vernarecovà, A.; Haz, L.; Dubinyovà, S.; Andrea, A.; Slàdkovà, I.; Surina, J. Extraction of phenolic and lipophilic compounds from spruce (Picea abies) bark using accelerated solvent extraction by ethanol. Wood Res. 2015, 6, 583-590.

2. Ekman, A.; Campos, M.S.; Lindhal, M.; Co, P.; Borjesson, E.N.; Karlsson, E.N.; Turner, C. Bioresource utilisation by sustainable technologies in new value-added biorefinery concepts -two case studies from food and forest industry. J. Clean. Prod. 2013, 57, 46-58. [CrossRef]

3. Co, M.; Fagerlund, A.; Engman, L.; Sunnerheim, K.; Sjoberg, P.J.; Turner, C. Extraction of antioxidants from spruce (Picea abies) bark using eco-friendly solvents. Phytochem. Anal. 2012, 23, 1-11. [CrossRef] [PubMed]

4. Kahkonen, M.P.; Hopia, A.I.; Vuorela, H.J.; Rauha, J.P.; Pihlaja, K.; Kujala, T.S.; Heinonen, M. Antioxidant activity of plant extracts containing phenolic compounds. J. Agric. Food Chem. 1999, 47, 3954-3962. [CrossRef]

5. Pan, H.; Lundgren, L.N. Phenolic extractives from root bark of Picea abies. Phytochemical 1995, 39, 1423-1428. [CrossRef]

6. Gabaston, J.; Richard, T.; Biais, B.; Waffo-Teguo, P.; Pedrot, E.; Jourdes, M.; Corio-Costet, M.F.; Mèrillon, M.J. Stilbenes from common spruce (Picea abies) bark as natural antifungal agent against downy mildew (Plasmopara viticola). Ind. Crops Prod. 2017, 103, 267-273. [CrossRef]

7. Hasan, M.; Bae, H. An overview of stress-induced resveratrol synthesis in grapes: Perspectives for resveratrol-enriched grape products. Molecules 2017, 22, 294. [CrossRef]

8. Smoliga, J.M.; Baur, J.A.; Hausenblas, H. Resveratrol and health: A comprehensive review of human clinical trials. Mol. Nutr. Food Res. 2011, 55, 1129-1141. [CrossRef]

9. Kursvietiene, L.; Staneviciene, I.; Morgidiene, A.; Bernatoniene, J. Multiplicity of effects and health benefits of resveratrol. Medicina 2016, 52, 148-155. [CrossRef]

10. Szkudelska, K.; Szkudelski, T. Resveratrol, obesity and diabetes. Eur. J. Pharm. 2010, 635, 1-8. [CrossRef]

11. Fogacci, F.; Tocci, G.; Presta, V.; Fratter, A.; Borghi, C.; Cicero, A.F. Effect of resveratrol on blood pressure: A systematic review and meta-analysis of randomized, controlled, clinical trials. Crit. Rev. Food Sci. Nutr. 2018, 59, 1-14. [CrossRef]

12. Rauf, A.; Imran, M.; Butt, M.S.; Nadeem, M.; Peters, D.G.; Mubarak, M.S. Resveratrol as an anti-cancer agent: A review. Crit. Rev. Food Sci. Nutr. 2018, 58, 1428-1447. [CrossRef] [PubMed]

13. Ratz-Łyko, A.; Arct, J. Resveratrol as an active ingredient for cosmetic and dermatological applications: A review. J. Cosmet. Laser Ther. 2019, 21, 84-90. [CrossRef] [PubMed]

14. Talmaciu, A.I.; Ravber, M.; Volf, I.; Knez, Z.; Popa, V. Isolation of bioactive compounds from spruce bark waste using sub- and supercritical fluids. J. Supercrit. Fluids 2016, 117, 243-251. [CrossRef]

15. Ghitescu, R.E.; Volf, I.; Carausu, C.; Buhlmann, A.M.; Glica, I.A.; Popa, V. Optimization of ultrasound-assisted extraction of polyphenols from spruce wood bark. Ultrason. Sonochem. 2015, 22, 535-541. [CrossRef]

16. Hatti-Kaul, R.; Tornvall, U.; Gustafsson, L.; Borjesson, P. Industrial biotechnology for the production of bio-based chemicals-A cradle-to-grave perspective. Trends Biotechnol. 2007, 25, 119-124. [CrossRef]

17. Herrero, M.; Cifuentes, A.; Ibanez, E. Sub- and supercritical fluid extraction of functional ingredients from different natural sources: Plants, food-by-products, algae and microalgae: A review. Food Chem. 2006, 98, 136-148. [CrossRef]

18. Chemat, F.; Rombaut, N.; Sicaire, A.G.; Meullemiestre, A.; Fabiano-Tixier, A.S.; Abert-Vian, M. Ultrasound assisted extraction of food and natural products. Mechanisms, techniques, combinations, protocols and applications. A review. Ultrason. Sonochem. 2017, 34, 540-560. [CrossRef] 
19. Garcì-Salas, P.; Morales-Soto, A.; Segura-Carretero, A.; Fernández-Gutiérrez, A. Phenolic compound extraction systems for fruit and vegetable samples. Molecules 2010, 15, 8813-8826. [CrossRef]

20. Pereira, C.G.; Meireles, M.A.A. Supercritical fluid extraction of bioactive compounds: Fundamentals, applications and economic perspectives. Food Bioprocess Technol. 2010, 3, 340-372. [CrossRef]

21. Nautyal, O.H. Food processing by supercritical carbon dioxide-review. EC Chem. 2016, 21, 111-135.

22. Spinelli, S.; Conte, A.; Lecce, L.; Padalino, L.; Del Nobile, M.A. Supercritical carbon dioxide extraction of brewer's spent grain. J. Supercrit. Fluids 2016, 107, 69-74. [CrossRef]

23. Mustafa, A.; Turner, C. Pressurized liquid extraction as a green approach in food and herbal plants extraction: A review. Anal. Chim. Acta 2011, 703, 8-18. [CrossRef] [PubMed]

24. Santos, D.T.; Veggi, P.C.; Meireles, M.A.A. Optimization and economic evaluation of pressurized liquid extraction of phenolic compounds from jabuticaba skins. J. Food Eng. 2012, 108, 444-452. [CrossRef]

25. Marinelli, V.; Padalino, L.; Nardiello, D.; Del Nobile, M.A.; Conte, A. New approach to enrich pasta with polyphenols from grape marc. J. Chem. 2015, 8, 1-8. [CrossRef]

26. Lucera, A.; Costa, C.; Marinelli, V.; Saccotelli, M.A.; Del Nobile, M.A.; Conte, A. Fruit and Vegetable By-Products to Fortify Spreadable Cheese. Antioxidants 2018, 7, 61. [CrossRef]

27. Sun, Y.; Qi, Y.; Mu, Z.; Wang, K. Quantitative determination of resveratrol in Polygonum cuspidatum and its anti-proliferative effect on melanoma A375 cells. Biomed. Res. 2015, 26, 750-754.

28. Veggi, P.C.; Prado, J.M.; Bataglioni, G.A.; Eberlin, M.N.; Meireles, M.A.A. Obtaining phenolic compounds from jatoba (Hymenaea courbaril L.) bark by supercritical fluid extraction. J. Supercrit. Fluids 2014, 89, 68-77. [CrossRef]

29. Salleh, L.M.; Rahman, R.A.; Selamat, J.; Hamid, A.; Sarker, M.Z.I. Optimization of extraction condition for supercritical carbon dioxide (SC- $\mathrm{CO}_{2}$ ) extraction of Strobhilantes Crispus (Pecah Kaca) leaves by response surface methodology. J. Food Process Technol. 2013, 4, 197-201.

30. Conde, E.; Hemming, J.; Smeds, A.; Reinoso, B.D.; Moure, A.; Willfor, S.; Domìnguez, H.; Parajò, J.C. Extraction of low-molar-mass phenolics and lipophilic compounds from Pinus pinaster wood with compressed $\mathrm{CO}_{2}$. J. Supercrit. Fluids 2013, 81, 193-199. [CrossRef]

31. Fabrowska, J.; Ibanez, E.; Leska, B.; Herrero, M. Supercritical fluid extraction as a tool to valorize underexploited freshwater green algae. Algal Res. 2016, 19, 237-245. [CrossRef]

32. Khaw, K.Y.; Parat, M.O.; Shaw, P.N.; Falconer, J.R. Solvent Supercritical Fluid Technologies to Extract Bioactive Compounds from Natural Sources: A Review. Molecules 2017, 22, 1186. [CrossRef] [PubMed]

33. Zaidulism, J.A.; Rahman, M.M.; Sharis, K.M.; Mohamed, A.; Sahena, F.; Jahurul, M.H.A.; Ghafoor, K.; Noriliani, N.A.N.; Omar, A.K.M. Techniques for extraction of bioactive compounds from plant materials: A review. J. Food Eng. 2013, 117, 426-436.

34. Rostagno, M.A.; Palma, M.; Barroso, C.G. Pressurized liquid extraction of isoflavones from soybeans. Anal. Chim. Acta 2004, 522, 169-177. [CrossRef]

35. Howard, L.; Pandjaitan, N. Pressurized liquid extraction of flavonoids from spinach. J. Food Sci. 2008, 73, 151-157. [CrossRef]

36. Zhao, H.; Dong, J.; Lu, J.; Chen, J.; Li, Y.; Shan, L.; Lin, Y.; Fan, W.; Gu, G. Effects of extraction solvent mixtures on antioxidant activity evaluation and their extraction capacity and selectivity for free phenolic compounds in barley (Hordeum vulgare L.). J. Agric. Food Chem. 2006, 54, 7277-7286. [CrossRef]

37. Hemwimol, S.; Pavasant, P.; Shotipruk, A. Ultrasound-assisted extraction of anthraquinones from roots of Morinda citrifolia. Ultrason. Sonochem. 2006, 13, 543-548. [CrossRef]

38. Thaiponga, K.; Boonprakoba, U.; Crosbyb, K.; Cisneros-Zevallosc, L.; Byrne, D.H. Comparison of ABTS, DPPH, FRAP, and ORAC assays for estimating antioxidant activity from guava fruit extracts. J. Food Compos. Anal. 2006, 19, 669-675. [CrossRef]

39. Youn, J.S.; Kim, Y.J.; Na, H.J.; Jung, H.R.; Song, C.K.; Kang, S.Y.; Kim, J.Y. Antioxidant activity and contents of leaf extracts obtained from Dendropanax morbifera LEV are dependent on the collecting season and extraction conditions. Food Sci. Biotechnol. 2019, 28, 201-207. [CrossRef]

40. Teixeira, T.S.; Vale, R.C.; Almeida, R.R.; Ferreira, T.P.S.; Guimarães, L.G.L. Antioxidant Potential and its Correlation with the Contents of Phenolic Compounds and Flavonoids of Methanolic Extracts from Different Medicinal Plants. Rev. Virtual Quim. 2017, 9, 1546-1559. [CrossRef] 
41. Chaudhari, G.M.; Mahajan, R.T. Comparative Antioxidant Activity of Twenty Traditional Indian Medicinal Plants and its Correlation with Total Flavonoid and Phenolic Content. Int. J. Pharm. Sci. Rev. Res. 2015, 30, 105.

42. Kareem, H.S.; Ariffin, A.; Nordin, N.; Heidelberg, T.; Abdul-Aziz, A.; Kong, K.W.; Yehye, W.A. Correlation of antioxidant activities with theoretical studies for new hydrazone compounds bearing a 3,4,5-trimethoxy benzyl moiety. Eur. J. Med. Chem. 2015, 103, 497-505. [CrossRef] [PubMed]

43. Du, F.Y.; Xiao, X.H.; Li, J.K. Application of ionic liquids in the microwave-assisted extraction of trans-resveratrol from Rhizma Polygoni Cuspidati. J. Chromatogr. A 2007, 1140, 56-62. [CrossRef] [PubMed]

44. Zupancic, S.; Lavric, Z.; Kristl, J. Stability and solubility of trans-resveratrol are strongly influenced by $\mathrm{pH}$ and temperature. Eur. J. Pharm. Biopharm. 2015, 93, 196-204. [CrossRef] [PubMed]

45. Garcìa-Pèrez, M.E.; Royer, M.; Herbette, G.; Desjardins, Y.; Pouliot, R.; Stevanovic, T. Picea mariana bark: A new source of trans-resveratrol and other bioactive polyphenols. Food Chem. 2012, 135, 1173-1182. [CrossRef] [PubMed]

(C) 2019 by the authors. Licensee MDPI, Basel, Switzerland. This article is an open access article distributed under the terms and conditions of the Creative Commons Attribution (CC BY) license (http://creativecommons.org/licenses/by/4.0/). 